\title{
An Asymmetric Organocatalytic Aldol Reaction of a Hydrophobic Aldehyde in Aqueous Medium Running in Flow Mode
}

\author{
Lukas Schober ${ }^{\mathrm{a}}$ \\ Shahilan Ratnam ${ }^{\mathrm{a}}$ \\ Yasunobu Yamashita \\ Niklas Adebar ${ }^{a}$ \\ Matthias Pieper ${ }^{\mathrm{a}}$ \\ Albrecht Berkessel ${ }^{b}(1)$ \\ Volker Hesselc,1 \\ Harald Gröger*a (D) \\ ${ }^{a}$ Chair of Organic Chemistry I, Faculty of Chemistry, Bielefeld \\ University, Universitätsstr. 25, 33615 Bielefeld, Germany \\ harald.groeger@uni-bielefeld.de \\ ${ }^{b}$ Department of Chemistry (Organic Chemistry), University of \\ Cologne, Greinstrasse 4, 50939 Cologne, Germany \\ c Micro Flow Chemistry \& Process Technology, Department of \\ Chemical Engineering and Chemistry, Eindhoven University of \\ Technology, P.O. Box 513, 5600 MB Eindhoven, The Nether- \\ lands
}

Dedicated to Professor Dr. Jürgen Martens on the occasion of his $70^{\text {th }}$ birthday

Published as part of the 50 Years SYNTHESIS - Golden Anniversary Issue

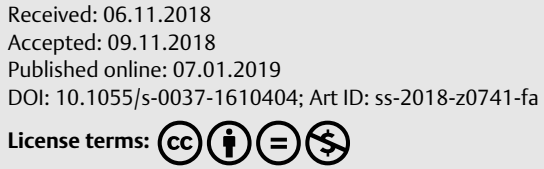

Abstract Reaction conditions have been identified to conduct a onepot asymmetric organocatalytic aldol reaction with a hydrophobic substrate in aqueous medium via a process running in flow mode. By employing a mixture of water and 2-propanol, a hydrophobic aldehyde and $3.6 \mathrm{~mol} \%$ of an organocatalyst, this microreactor process affords the desired aldol adduct with a conversion of $74 \%$ and an enantioselectivity of $89 \%$ after a reaction time of 60 minutes.

Key words aldol reaction, asymmetric catalysis, continuously running processes, flow chemistry, organocatalysis, water

Enantioselective chemoenzymatic one-pot processes represent an attractive and efficient methodology in synthetic organic chemistry for the construction of chiral molecules. ${ }^{2}$ However, so far, only a limited number of one-pot processes with combined chemo- and biocatalysis have been reported, ${ }^{2}$ and the combination of such types of reactions in a one-pot and flow mode is, to the best of our knowledge, unknown so far. At the same time, flow processes $^{3}$ have gained increasing importance, and the development of commercialized flow processes for pharmaceutical purposes also meet the regulatory guidelines of the U.S. Food and Drug Administration (FDA) and the European Medicines Agency (EMA). ${ }^{4}$ There are a range of advantages when conducting processes in a continuously operating mode. For example, the quality of the desired product can

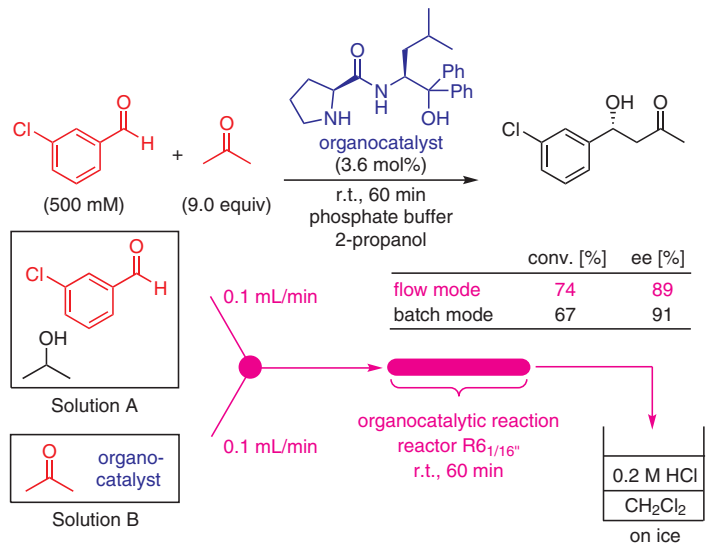

be more easily ensured and numbering up of flow modules represents an elegant method for increasing the production scale without facing scale-up concerns.

One of the current challenges in the field of chemoenzymatic flow processes consists of developing a proof of concept that reactions from different 'worlds' of catalysis, namely chemo- and biocatalysis, can be merged utilizing an aqueous reaction medium (as the general reaction medium of choice when planning to apply enzyme-catalyzed reaction steps). As a 'benchmark system' for our study in this field, we chose the cascade synthesis of 1,3-diols starting from aldehydes and acetone through a combination of an initial organocatalytic aldol reaction and a subsequent biocatalytic ketone reduction using an alcohol dehydrogenase. ${ }^{5}$ The concept of this model process is illustrated in Scheme 1. The motivation to focus on this specific synthesis is due to the fact that, for the batch mode, efficient versions of such a one-pot process have already been developed, thus representing an ideal starting point for our study. ${ }^{5}$

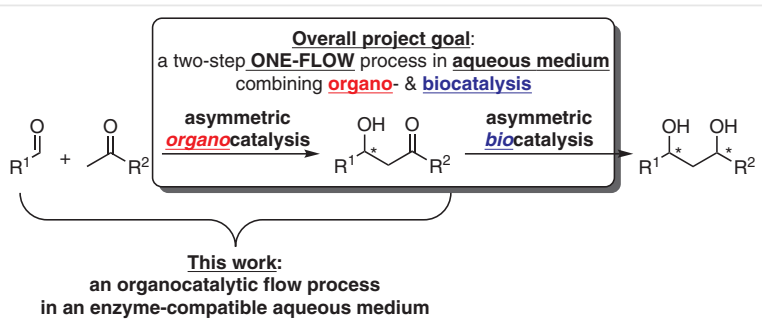

Scheme 1 Combining two reactions from different catalytic 'worlds' namely organo- and biocatalysis, in a ONE-FLOW process 
(from left to right; starting with upper line first) Lukas Schober M. Sc. was born in Georgsmarienhütte, Germany in 1994. He studied chemistry and graduated with a Bachelor of Science from the Faculty of Chemistry, Bielefeld University in 2015. He continued to study as a master student in the group of Prof. Dr. Harald Gröger and also joined the workgroups of Prof. Dr. Hiroaki Sasai and Prof. Dr. Shuji Akai in Osaka University for research stays. His Master thesis, which was conducted at Osaka University and Bielefeld University, focused on the development of novel asymmetric vanadium catalysed reactions. Since 2018 he is working as a Ph.D. student in the ONE-FLOW consortium, and his research centers on the implementation of new catalytic cascades in flow processes. His research interests includes chemoand biocatalysis, flow chemistry and the development of new routes to asymmetric building blocks. Shahilan Ratnam was born in 1997 in Bielefeld, Germany. He received his B.Sc. degree in Chemistry from Bielefeld University in 2018. During his bachelor thesis he focused on the asymmetric organocatalytic aldol reaction in batch and flow in the research group of Prof. Dr. Gröger. Now he is a M.Sc student at Bielefeld University. Yasunobu Yamashita was born in Aichi prefecture, Japan, in 1987. He graduated from the Faculty of Pharmacy of Keio University in 2012 (Bachelor degree) and obtained his Master degree from the Graduate School of Pharmaceutical Sciences at Keio University in 2014. In 2017 he received his PhD from the Graduate school of Pharmaceutical Sciences, Keio University under the supervision of Prof. Dr. Sugai. Since 2017 he is a post-doctoral fellow in the research group of Prof. Dr. Gröger at the Bielefeld University. His research interest includes enzyme-mediated organic synthesis. Niklas Adebar obtained his M.Sc. in organic synthesis in 2018 from the Bielefeld University, Germany with Prof. Harald Gröger focusing on the development of flow systems utilizing bio- and chemo catalysts. Within his M.Sc. studies, he joined the group of Prof. Thomas Wirth at Cardiff University, UK for a research stay. Currently he is a Ph.D. student at Bielefeld University in the group of Prof. Harald Gröger. His research interests besides the combination of biocatalysis and flow chemistry is the application of renewable feedstocks in bulk chemical processes. Matthias Pieper was born in Lübbecke, Germany in 1987. He studied chemistry at Bielefeld University and was graduated in 2012 with a Bache-

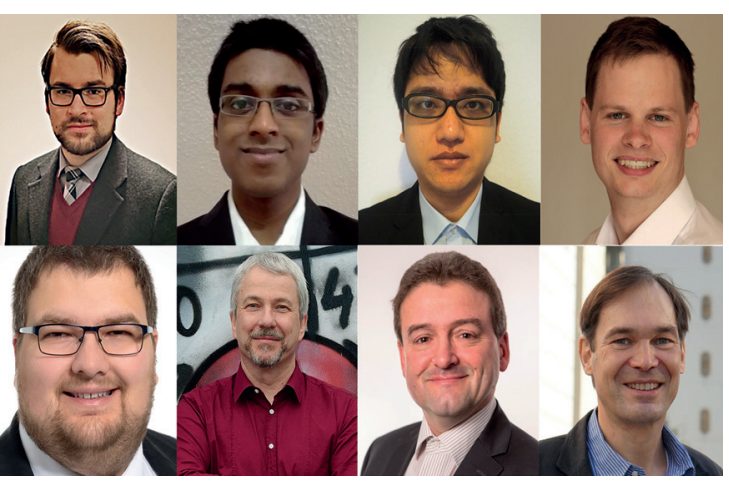

Prof. Hessel was appointed as Deputy Dean (Research) and Full Professor at the School of Chemical Engineering in the ECMS Faculty at the University of Adelaide, Australia. He is (co)author of $>450$ peer-reviewed (h-index: 54). He received the AIChE Award "Excellence in Process Development Research" in 2007, the ERC Advanced Grant “Novel Process Windows" in 2010, the ERC Proof of Concept Grant in 2017, the IUPAC ThalesNano Prize in Flow Chemistry in 2016, the FET OPEN Grant in 2016, and the ERC Synergy Grant 2018. He was authority in the 35-man teamed Parliament

lor of Science. During his bachelor thesis he investigated an enzymatic aldol reaction and gained insight to the field of biocatalysis. He continued his studies in organic chemistry and was graduated in 2015 with a Master of Science. In his master thesis he also focused on the development of processes running in a flow mode. Since 2015 he is working as a Ph.D. student in the group of Prof. Dr. Harald Gröger. His research interests are the development of ecologica and economical routes for the synthesis of pharmaceutically active compounds as well as the transfer of these reactions to a flow setup. Albrecht Berkessel was born in Saarlouis, Germany, in 1955. He obtained his Diplom in 1982 at the University of Saarbrücken. For his $\mathrm{PhD}$ studies, he joined the laboratory of Professor Waldemar Adam at the University of Würzburg. After completing his PhD studies in 1985, he joined the research group of Professor Ronald Breslow at Columbia University, New York. His habilitation at the University of Frankfurt/Main (associated to Professor Gerhard Quinkert) was completed in 1990. In 1992, he became Associate Professor at the University of Heidelberg. Since 1997, he is a Full Professor of Organic Chemistry at the University of Cologne. His research interests center around various aspects of catalysis research, such as mechanism and method development in metal-based catalysis and organocatalysis, biomimetic and medicinal chemistry. Prof. Dr. Volker Hessel studied chemistry at Mainz University (PhD in organic chemistry, 1993). In 1994 he entered the Institut für Mikrotechnik Mainz GmbH. In 2002, Prof. Hessel was appointed Vice Director R\&D at IMM and in 2007 as Director R\&D. In 2005 and 2011, Prof. Hessel was appointed as Part-time and Full Professor at Eindhoven University of Technology, respectively. He was Honorary Professor at TU Darmstadt, Germany 2009-2018, and is Guest Professor at Kunming University of Science and Technology, China (2011-).
Enquete Commission "Future of the Chemical Industry" in Nordrhine-Westfalia. Prof. Hessel is in the Science Advisory Board for the GSK-Singapore Partnership for Green and Sustainable Manufacturing. Harald Gröger was born in Erlangen, Germany, in 1968. He studied Chemistry at the Universities of Erlangen-Nürnberg and Oldenburg and received his diploma degree in Chemistry from the University of Oldenburg in 1994. His doctoral thesis he completed at the University of Oldenburg in 1997 under the supervision of Prof. Dr. Martens. After staying as a postdoctoral fellow at the University of Tokyo in the group of Prof. Dr. Shibasaki, he joined the research department Chemische Forschung of SKW Trostberg AG in 1998. After the merger with Degussa-Hüls AG to Degussa AG in 2001, he became project manager in the Project House Biotechnology of Degussa AG. From 2004 to 2006 he worked as a senior project manager at the research unit Service Center Biocatalysis of Degussa AG. From 2006 to 2011 he was W2-professor (associate professor) for organic chemistry at the University of Erlangen-Nürnberg, and since April 2011 he is a W3-professor (full professor) for Organic Chemistry at Bielefeld University. He was awarded, e.g., the Degussa Innovation Award 2003 (category: new products), the Degussa Innovation Award 2005 (category: new or improved processes), the Carl-Duisberg-Memorial-Prize 2008 of the German Chemical Society (GDCh), the Otto Roelen Medal 2014 from the DECHEMA (Society for Chemical Engineering and Biotechnology) and the German Catalysis Society (GeCatS) and a visiting professorship at Osaka University in 2014. His main research areas center on the use of biocatalysts in organic synthesis, comprising, e.g., the development of industrially feasible biotransformations and the combination of bio- and chemocatalysis towards chemoenzymatic one-pot processes. 
In order to achieve compatibility of the process conditions with the flow mode requirements, initial focus was directed toward the identification of suitable reaction conditions enabling the organocatalytic aldol reaction and biocatalytic reduction to be run in aqueous medium in flow mode. However, the reported conditions for the initial asymmetric organocatalytic aldol reaction step in batch processes $^{5-7}$ appeared to be problematic for flow purposes due to the heterogeneity of the reaction mixture in aqueous media. Thus, a major task was to identify solvent conditions for the organocatalytic aldol reaction in aqueous medium being also suitable for the flow mode. For this proof of concept study, we chose the asymmetric aldol reaction of acetone with 3-chlorobenzaldehyde (1) utilizing organocatalyst $\mathbf{2},{ }^{6,8}$ developed by the Singh group, as a starting point due to the excellent results obtained for this reaction in batch mode. ${ }^{5-7}$ Herein, we report our results achieved within the EU network research project ONE-FLOW ${ }^{9}$ on extending this asymmetric organocatalytic reaction with a hydrophobic aldehyde in aqueous medium toward a flow mode process.

As the initial step, we searched for a reaction medium that was suitable for conducting the organocatalytic aldol reaction of 3-chlorobenzaldehyde (1) and acetone with organocatalyst $\mathbf{2}$ in flow mode. When utilizing brine as the preferred aqueous medium in earlier studies on this aldol reaction with 9 equivalents of acetone and $0.5 \mathrm{~mol} \%$ of organocatalyst 2 running in batch mode, ${ }^{5 b, c, 6}$ a mixture with a milky consistency was formed, even in the presence of 2propanol, which appeared to be disadvantageous for a flow process (Table 1 , entry 1 ). Thus, we replaced brine with a phosphate buffer with a $\mathrm{pH}$ of 7 and again added 2-propanol to enhance the solubility of the hydrophobic aldehyde $\mathbf{1}$ (Table 1, entry 2). This solvent system would be beneficial since it is suitable for the biocatalytic reduction as well, which is planned to be combined with the organocatalytic reaction at a later stage. Furthermore, in earlier work we demonstrated that the organocatalytic aldol reaction also proceeds in this solvent system..$^{5 a}$ When applying this combination of buffer ( $\mathrm{pH} 7$ ) and 2-propanol as the solvent system, we were pleased to find a clear solution of the hydrophobic substrate. Additionally, for the organocatalyst $\mathbf{2}$, we found that up to $3.6 \mathrm{~mol} \%$ can be utilized without forming a precipitate. Accordingly, this solvent system was chosen for our further studies.

Having a reaction medium with a consistency fulfilling the requirements for a flow process in hand, next we focused on the development of a suitable quenching method for the reaction mixture. As the reaction time of the flow process is very short ranging from 5 to $60 \mathrm{~min}$, an efficient quenching method for this system is of utmost importance for a precise determination of the conversion and enantiomeric excess after such short reaction times. Such a quenching method should stop the flow reaction immediately. Toward this end, a two-phase system was used, which consists of an aqueous hydrochloric acid phase and methy-
Table 1 Screening for a Suitable Homogeneous Reaction Medium

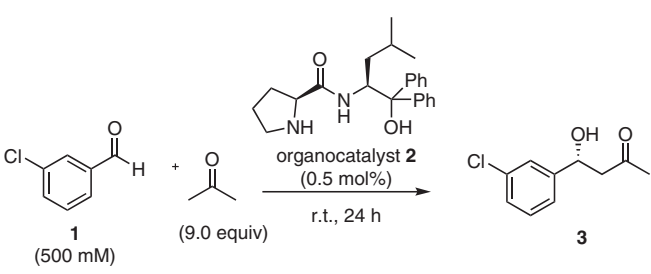

\begin{tabular}{lll}
\hline Entry & Reaction Medium & Consistency \\
\hline 1 & brine/2-propanol & milky \\
2 & buffer $(\mathrm{pH} \mathrm{7)/2-propanol}$ & clear \\
\hline
\end{tabular}

lene chloride as an organic phase (Table 2). Once the reaction solution leaves the flow reactor and is collected in the two-phase system, the hydrochloric acid protonates the catalyst, therefore enhancing its solubility in water and decreases its catalytic activity dramatically. While the catalyst remains in the aqueous phase the starting material and product are extracted in situ into the organic phase and can be separated from the catalyst. To further suppress the continuation of the aldol reaction while being collected in the storage container after the flow reaction, we cooled the mixture to $0{ }^{\circ} \mathrm{C}$. It should be added that validation of this method has been done by means of a $1: 1$ mixture of starting material and product, which led to a negligible change in the ratio of $\mathbf{1}$ and $\mathbf{3}$ within 5 minutes and a slight change after 30 minutes (Table 2). Thus, the storage time of the collected solution in these containments after completion of the flow process and prior to the work-up should not exceed 15 minutes.

Table 2 Concept and Validation of the Quenching Method

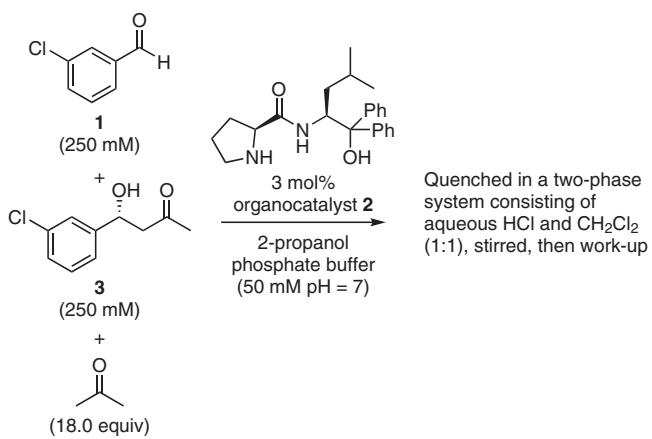

\begin{tabular}{llll}
\hline Entry & Stirring time & $\mathbf{1}(\%)^{\mathrm{a}}$ & $\mathbf{3}(\%)^{\mathrm{a}}$ \\
\hline 1 & 0 min & 51 & 49 \\
2 & $5 \mathrm{~min}$ & 50 & 50 \\
3 & $15 \mathrm{~min}$ & 48 & 52 \\
4 & $30 \mathrm{~min}$ & 47 & 53 \\
\hline
\end{tabular}

${ }^{a}$ Determined via ${ }^{1} \mathrm{H}$ NMR spectroscopy. 
With an appropriate quenching method in hand, we started to adapt the conditions of the batch reaction to the requirements for a flow process in order to use such reaction parameters in a flow process. The first challenge consisted of overcoming the long reaction time of 24 hours, which is compatible with batch processes but not suitable for processes running in flow mode. Thus, we focused on identifying reaction conditions which enable the asymmetric organocatalytic aldol reaction with high conversion and enantioselectivity, but also within a short reaction time. As a target reaction time frame, we defined $15-60$ minutes and investigated the influence of the catalyst loading (0.5$3.6 \mathrm{~mol} \%$ ) and temperature (r.t. and $40{ }^{\circ} \mathrm{C}$ ), in combination with short reaction times, on the organocatalytic aldol reaction in terms of conversion and enantioselectivity. The results of this reaction-parameter screening are summarized in Table 3.

It turned out that in the presence of very low catalyst loadings of $0.5 \mathrm{~mol} \%$ and $1.5 \mathrm{~mol} \%$, even at an elevated temperature of up to $40{ }^{\circ} \mathrm{C}$, the reaction time of 60 minutes was not sufficient to obtain a high conversion and did not exceed $25 \%$ in these cases (Table 3, entries 1, 2 and 4-9). On the other hand, it is noteworthy that a significantly higher catalyst loading of $3.0 \mathrm{~mol} \%$ in combination with a high

Table 3 Screening of the Aldol Reaction Conditions for the Batch Mode

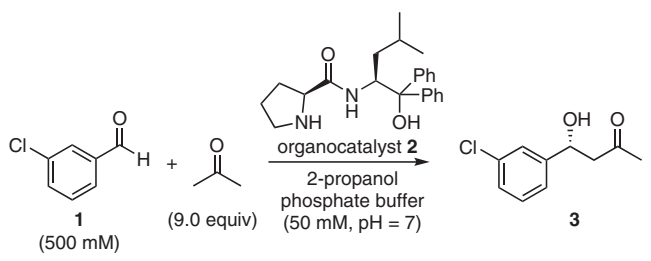

\begin{tabular}{llllll}
\hline Entry & Cat. amount & Temp & Time & Conv. & ee \\
\hline 1 & $0.5 \%$ & $40{ }^{\circ} \mathrm{C}$ & $60 \mathrm{~min}$ & $3 \%$ & $81 \%$ \\
2 & $1.5 \%$ & $40{ }^{\circ} \mathrm{C}$ & $60 \mathrm{~min}$ & $25 \%$ & $79 \%$ \\
3 & $3.0 \%$ & $40{ }^{\circ} \mathrm{C}$ & $60 \mathrm{~min}$ & $60 \%$ & $61 \%$ \\
4 & $0.5 \%$ & r.t. & $15 \mathrm{~min}$ & $1 \%$ & $73 \%$ \\
5 & $0.5 \%$ & r.t. & $30 \mathrm{~min}$ & $5 \%$ & $90 \%$ \\
6 & $0.5 \%$ & r.t. & $60 \mathrm{~min}$ & $3 \%$ & $89 \%$ \\
7 & $1.5 \%$ & r.t. & $15 \mathrm{~min}$ & $6 \%$ & $82 \%$ \\
8 & $1.5 \%$ & r.t. & $30 \mathrm{~min}$ & $11 \%$ & $88 \%$ \\
9 & $1.5 \%$ & r.t. & $60 \mathrm{~min}$ & $21 \%$ & $77 \%$ \\
10 & $3.0 \%$ & r.t. & $15 \mathrm{~min}$ & $13 \%$ & $89 \%$ \\
11 & $3.0 \%$ & r.t. & $30 \mathrm{~min}$ & $29 \%$ & $90 \%$ \\
12 & $3.0 \%$ & r.t. & $60 \mathrm{~min}$ & $62 \%$ & $89 \%$ \\
13 & $3.6 \%$ & r.t. & $15 \mathrm{~min}$ & $20 \%$ & $90 \%$ \\
14 & $3.6 \%$ & r.t. & $30 \mathrm{~min}$ & $47 \%$ & $91 \%$ \\
15 & $3.6 \%$ & r.t. & $60 \mathrm{~min}$ & $67 \%$ & $91 \%$ \\
\hline
\end{tabular}

${ }^{a}$ Cat. amount $=$ catalytic amount $(\%$ is defined as mol\% in case of Cat. amount); Conv. = conversion. temperature of $40{ }^{\circ} \mathrm{C}$ led to an improved conversion of $60 \%$, but with a relatively low ee value of only $61 \%$ ee (Table 3 , entry 3 ). The decrease of the ee value at an increased catalyst loading is in accordance with previous results, ${ }^{5 c, 7 a}$ and can be rationalized by a change from a kinetically controlled to a thermodynamically controlled reaction.

In contrast, on decreasing the reaction temperature to room temperature, and notwithstanding the low conversions when using lower catalyst loadings ( 0.5 and 1.5 $\mathrm{mol} \%$ ), the ee values increased up to $90 \%$ (Table 3 , entries $4-$ 9 ). Thus, we became interested in studying the impact of higher catalyst loadings while maintaining the reaction temperature at room temperature (Table 3, entries 10-15). Thus, on increasing the catalyst loadings to 3.0 and 3.6 $\mathrm{mol} \%$, respectively, we were pleased to find that even within a short reaction time of 60 minutes the formation of the desired aldol now proceeded with increased conversions of $62 \%$ and $67 \%$ and with high enantioselectivities of $89 \%$ and $91 \%$, respectively (Table 3 , entry 12 and 15 ).

Thus, as a result of this reaction-parameter study on the organocatalytic aldol reaction in batch mode, it turned out that the combination of the desired short reaction time of 60 minutes in combination with loadings of 3.0 and 3.6 mol\% of the organocatalyst 2 gave the best results (Table 3, entries 12 and 15 ). Since a precipitate was formed when using a loading exceeding $3.6 \mathrm{~mol} \%$ of organocatalyst 2 , the reaction conditions based on a catalyst loading of $3.6 \mathrm{~mol} \%$ of 2 (according to Table 3, entry 15) were chosen for our subsequent studies on the extension of this asymmetric organocatalytic reaction toward a process running in flow mode.

In order to develop a flow process for this asymmetric catalytic aldol reaction in aqueous medium (which would be, to best of our knowledge, the first asymmetric organocatalytic reaction with a hydrophobic substrate in water running in flow mode), we conducted the reaction in a capillary-type tube reactor using a catalyst loading of $3.6 \mathrm{~mol} \%$ of 2 . The concept of this flow process, which is shown schematically in Scheme 2, a and b, is based on the combination of two aqueous buffer/2-propanol solutions $A$ and $B$ bearing the aldehyde in $A$ and catalyst as well as acetone acting as a co-solvent and reagent in B. The flow reactor itself can be tailored to the desired individual length and diameter resulting in different residence times based on the set flow rate, while not comprising the hydrodynamics and assorted heat and mass transfer (Scheme 2, b and Table 4).

Thus, we carried out the reaction in several different flow reactors (diameter: $1 / 16^{\prime \prime}$; length: $9.5-152 \mathrm{~cm}$ ) with flow rates ranging from $0.0125 \mathrm{~mL} / \mathrm{min}$ to $0.2 \mathrm{~mL} / \mathrm{min}$ resulting in residence times between 15 and 60 minutes. The results are summarized in Table 4 and showed two interesting general trends. First, it seems that while maintaining the residence time constant, high flow rates led to higher conversions compared to slow flow rates. 
(a)

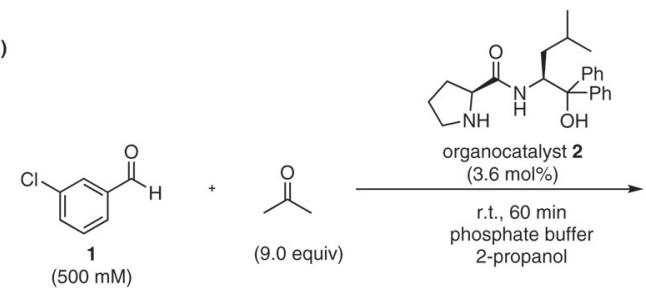

(b)

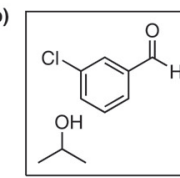

Solution A

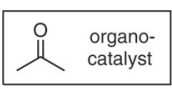

Solution B

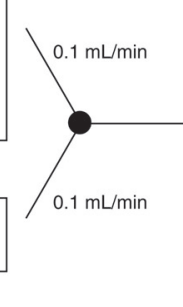

$\underbrace{\longrightarrow}_{\begin{array}{c}\text { organocatalytic reaction } \\ \text { reactor } \mathrm{R} 6_{1 / 16^{\prime \prime}}\end{array}}$

r.t., $60 \mathrm{~min}$

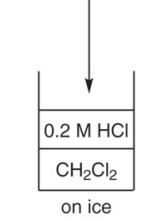

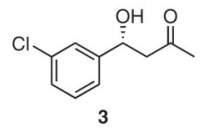

Scheme 2 Asymmetric organocatalytic aldol reaction with a hydrophobic aldehyde in aqueous medium operating in flow mode

Table 4 Screening of Parameters (Reactor Length and Flow Rate) in Flow Mode

\begin{tabular}{|c|c|c|c|c|c|}
\hline \multirow{4}{*}{$\begin{array}{l}\text { Flow rate } \\
\text { (mL/min) }\end{array}$} & \multicolumn{5}{|c|}{ Reactor length $(\mathrm{cm})$; reactor volume $(\mathrm{mL})$} \\
\hline & & & & & \\
\hline & $9.5 ; 0.19$ & $19 ; 0.38$ & $38 ; 0.75$ & $76 ; 1.5$ & $152 ; 3.0$ \\
\hline & \multicolumn{5}{|c|}{ Residence time (min) } \\
\hline 0.2 & - & - & - & - & 15 \\
\hline 0.1 & - & - & - & 15 & 30 \\
\hline 0.05 & - & - & 15 & 30 & 60 \\
\hline 0.025 & - & 15 & 30 & 60 & - \\
\hline 0.0125 & 15 & 30 & 60 & - & - \\
\hline \multirow{4}{*}{$\begin{array}{l}\text { Flow rate } \\
(\mathrm{mL} / \mathrm{min})\end{array}$} & \multicolumn{5}{|c|}{ Reactor length $(\mathrm{cm})$; reactor volume $(\mathrm{mL})$} \\
\hline & R1 & $\mathrm{R} 2$ & R3 & R4 & R5 \\
\hline & $9.5 ; 0.19$ & $19 ; 0.38$ & $38 ; 0 . / 5$ & 16; 1.5 & \\
\hline & \multicolumn{5}{|c|}{ Conversion (\%); ee (\%) } \\
\hline 0.2 & - & - & - & - & $22 ; 88$ \\
\hline 0.1 & - & - & - & $15 ; 85$ & $28 ; 87$ \\
\hline 0.05 & - & - & $17 ; 89$ & $31 ; 89$ & $52 ; 88$ \\
\hline 0.025 & - & $16 ; 89$ & $23 ; 88$ & $44 ; 86$ & - \\
\hline 0.0125 & $14 ; 89$ & 22; 90 & $31 ; 85$ & - & - \\
\hline
\end{tabular}

Second, in longer reactors, higher conversions were observed than in shorter reactors. Both indicate the positive impact of turbulence on the reaction course. For example, a conversion of $52 \%$ with an enantioselectivity of $88 \%$ ee was achieved when using reactor $\mathrm{R} 5$ with a flow rate of 0.05 $\mathrm{mL} / \mathrm{min}$ in 60 minutes (Table 4), and this result is already in the range of the batch experiments (Table 3 ).
Since we were interested in further improving the performance of the flow process, we carried out reactions in even longer reactors in order to operate the process at even more elevated flow rates. When conducting the experiment in reactor $R 6_{1 / 16}$ " at a flow rate of $0.2 \mathrm{~mL} / \mathrm{min}$, an increased conversion of $74 \%$ in combination with a high enantioselectivity of $89 \%$ was obtained (Table 5 ). In addition, we carried out the reaction in reactor $R 6_{1 / 32}$ ", which has a smaller inner diameter but is of the same length as $R 6_{1 / 16^{\prime \prime}}$, thus reducing the flow rate to only $0.05 \mathrm{~mL} / \mathrm{min}$ in order to maintain the same residence time. Nevertheless, we achieved comparable results after 60 minutes, obtaining the desired product 3 with a slightly decreased conversion of $69 \%$ but still with a high enantioselectivity of $90 \%$ (Table 5 ).

\begin{tabular}{|c|c|c|}
\hline \multirow{3}{*}{$\begin{array}{l}\text { Flow rate } \\
(\mathrm{mL} / \mathrm{min})\end{array}$} & \multicolumn{2}{|c|}{ Reactor length $(\mathrm{cm})$; reactor volume $(\mathrm{mL})$; diameter $(\mathrm{mm})$} \\
\hline & $\begin{array}{l}\mathrm{R}_{1 / 16^{\prime \prime}} \\
606 ; 12 ; 1.59\end{array}$ & $\begin{array}{l}\mathrm{R}_{1 / 32 \prime \prime} \\
697 ; 3.0 ; 0.8\end{array}$ \\
\hline & \multicolumn{2}{|c|}{ Residence time (min); conversion (\%); ee (\%) } \\
\hline 0.4 & $30 ; 47 ; 89$ & - \\
\hline 0.2 & $60 ; 74 ; 89$ & - \\
\hline 0.05 & - & $60 ; 69 ; 90$ \\
\hline
\end{tabular}

As the flow rate and length of the reactor turned out to be of significance for the conversion when operating at the same residence time, we assumed that this might be due to their impact on mixing and convection, which is the hydrodynamic effect relevant under such flow conditions governing mass transfer. Since the mixing effect can be easily visu- 
alized by using solutions $A$ and $B$ of different color (according to the setup in Scheme 2, b), we colored one solution with Coomassie Brilliant Blue. As shown in Scheme 2, c, very fast mixing occurs, which also indicates that no laminar flow is created in any of our reactions.

When comparing the best organocatalytic aldol reactions in batch and flow mode within our present study under comparable reaction conditions (e.g., in terms of reaction time/residence time and catalyst loading), the best organocatalytic flow reaction was accomplished at room temperature in reactor $R 6_{1 / 16^{\prime \prime}}$ within a residence time of only 60 minutes. As a result, under these conditions, the conversion reached $74 \%$ and a high enantioselectivity of $89 \%$ ee was obtained (Table 5 and Scheme 3). Thus, the result of this flow process is nearly identical and even slightly superior to that obtained for the analogous batch process, which gave a slightly lower conversion of $67 \%$ and an enantioselectivity of $91 \%$ ee. A comparison of these best asymmetric organocatalytic aldol reactions in batch and flow mode, respectively, is shown in Scheme 3.
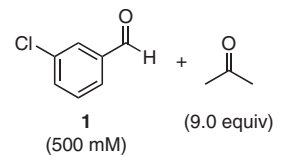

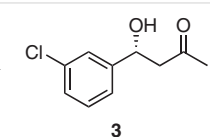

3 conv. [\%] ee [\%]

\begin{tabular}{lcr} 
& conv. [\%] & ee [\%] \\
\hline flow mode & 74 & 89
\end{tabular}

Scheme 3 Comparison of the best asymmetric organocatalytic aldol reactions at a reaction and residence time of 60 minutes running in batch and flow mode

The similar conversions in both flow and batch mode are also in accordance with the reaction kinetics theory of ideal continuously operating plug-flow and ideal discontinuously operating stirring-tank reactors. Assuming homogeneous reaction conditions and ideal conditions, a reaction proceeding in a plug-flow reactor and a stirring-tank reactor would lead to the same conversion (as a specific volume segment of the reaction mixture in a plug flow can then be considered as a 'micro-scale batch reactor volume').

In conclusion, a proof of concept has been demonstrated in which the asymmetric organocatalytic aldol reaction with hydrophobic substrates in water can be conducted efficiently in a process running in flow mode with short residence times of, e.g., 60 minutes. Besides being suitable for flow purposes, a further benefit of the identified reaction conditions is their high compatibility with enzymatic reduction reactions, since the biocatalytic reduction process needs exactly this reaction medium consisting of buffer $(\mathrm{pH}$ 7) and 2-propanol. Thus, the realized organocatalytic aldol reaction is expected to represent a suitable basis for the planned combination with a biocatalytic reduction reaction toward a chemoenzymatic process running in a one-pot and flow mode (ONE-FLOW process). The development of such a process is currently in progress.

All standard reagents were purchased from commercial sources and were used without further purification. Singh catalyst (2) was prepared according to the literature. ${ }^{8}{ }^{1} \mathrm{H}$ NMR spectra were recorded on a Bruker Avance 500 spectrometer. Analytical HPLC was carried out with a JASCO LC Net II/ADC using a UV-1575 UV/Vis detector and a Daicel Chiralpak ${ }^{\circledR}$ AD-H column. Glass reaction vials $(10 \mathrm{~mL}$ ) (which are kept at the desired temperature in an aluminum block) were used for batch reactions. The applied microreactors were made from Teflon tubes (1/16" id; $0.0198 \mathrm{~mL} / \mathrm{cm}$ and 1/32" id; $0.00503 \mathrm{~mL} / \mathrm{cm}$ ). For installation, the reactors were connected to the two syringes through a three-way piece $\left(0.05^{\prime \prime}\right.$ id for $1 / 16^{\prime \prime}$ tubes and 0.02 " id for $1 / 32$ " tubes) and two Teflon tubes (1/16" id; $20 \mathrm{~cm}$ ). The outlet was connected to the quenching solution, which was cooled to $0{ }^{\circ} \mathrm{C}$. The reactors were prepared from 1/16" tubing (R1: $9.5 \mathrm{~cm}, 0.19 \mathrm{~mL}$; R2: $18.9 \mathrm{~cm}, 0.38$ mL; R3: $37.9 \mathrm{~cm}, 0.75 \mathrm{~mL}$; R4: $75.8 \mathrm{~cm}, 1.5 \mathrm{~mL}$; R5: $151.6 \mathrm{~cm}, 3 \mathrm{~mL}$; $\mathrm{R}_{1 / 16^{\prime \prime}}: 606 \mathrm{~cm}, 12 \mathrm{~mL}$ ) and 1/32" tubing (R6 $\left.6_{1 / 32^{\prime \prime}}: 597 \mathrm{~cm}, 3 \mathrm{~mL}\right)$. If necessary, the reactors were adjusted to the desired temperature by means of a water bath fitted with a thermostat. A Legat ${ }^{\circledR} 200$ syringe pump from KD Scientific Inc. (84 October Hill Road, Holliston, MA 01756, USA; www.kdscientific.com) was used with commercially available $50 \mathrm{~mL}$ plastic syringes $\left(\right.$ Terumo ${ }^{\circledR}$ ).

\section{Organocatalytic Aldol Reactions in Batch Mode According to Table 3; General Procedure}

To a solution of 3-chlorobenzaldehyde (1) $70.3 \mathrm{mg}, 0.5 \mathrm{mmol}$ ), 2-propanol $(260 \mu \mathrm{L})$ and phosphate buffer $(50 \mathrm{mM}, \mathrm{pH}=7,180 \mu \mathrm{L})$, which has been adjusted to the desired reaction temperature, was added a solution containing Singh's catalyst (2) (0.92-6.60 mg, 0.0025-0.018 $\mathrm{mmol})$ in 2-propanol $(20 \mu \mathrm{L})$ and acetone $(330 \mu \mathrm{L}, 4.5 \mathrm{mmol})$, and the resulting mixture was stirred at room temperature or at $40{ }^{\circ} \mathrm{C}$ for $15-$ $60 \mathrm{~min}$. The mixture was added to $\mathrm{CH}_{2} \mathrm{Cl}_{2} / 2.0 \mathrm{M} \mathrm{HCl}$ (aq) solution (3 $\mathrm{mL} / 3 \mathrm{~mL}$ ) at $0{ }^{\circ} \mathrm{C}$. The organic materials were extracted with $\mathrm{CH}_{2} \mathrm{Cl}_{2}$ and concentrated in vacuo. The conversions were determined from the ${ }^{1} \mathrm{H}$ NMR spectra of the crude reaction mixtures. The ee values were determined by chiral HPLC after preparative TLC (Chiralpak ${ }^{\circledR}$ AD-H column, hexane/2-propanol, 95:5, flow: $1.0 \mathrm{~mL} / \mathrm{min}, 220 \mathrm{~nm}$ ). Retention time (min): 14.2 [(R)-3], $16.4[(S)-3]$.

\section{(R)-4-(3-Chlorophenyl)-4-hydroxybutan-2-one (3)}

${ }^{1} \mathrm{H} \mathrm{NMR}\left(400 \mathrm{MHz}, \mathrm{CDCl}_{3}\right): \delta=2.18(\mathrm{~s}, 3 \mathrm{H}), 2.80-2.82(\mathrm{~m}, 2 \mathrm{H}), 5.10-$ $5.12(\mathrm{~m}, 1 \mathrm{H}, \mathrm{CH}), 7.19-7.29(\mathrm{~m}, 4 \mathrm{H})$.

The analytical data are in accordance with those reported in the literature. ${ }^{5 c}$

Organocatalytic Aldol Reaction in Flow Mode According to Scheme 2

Solution A [3-chlorobenzaldehyde (1) (2.1085 g, $15 \mathrm{mmol}$ ), 2-propanol (7.8 mL) and phosphate buffer $(50 \mathrm{mM}, \mathrm{pH}=7,5.4 \mathrm{~mL})]$ and solution B [Singh's catalyst (2) (197.9 mg, $0.54 \mathrm{mmol}$ ), 2-propanol (0.6 $\mathrm{mL})$, acetone $(9.9 \mathrm{~mL}, 135 \mathrm{mmol})$ and phosphate buffer $(50 \mathrm{mM}, \mathrm{pH}=$ $7,4.5 \mathrm{~mL}$ )] were transferred into $50 \mathrm{~mL}$ plastic syringes ( $28 \mathrm{~mm}$ diameter), and pumped with a flow rate of $0.1 \mathrm{~mL} / \mathrm{min}$ through a microreactor at room temperature (r.t.). The equilibration time was adjusted to the twofold retention time (e.g., $120 \mathrm{~min}$ in case of $60 \mathrm{~min}$ residence time). Subsequently, the eluted sample was collected and quenched by dropwise addition into a solution of $\mathrm{CH}_{2} \mathrm{Cl}_{2} / 2.0 \mathrm{M} \mathrm{HCl}$ 
(aq) $(3 \mathrm{~mL} / 3 \mathrm{~mL})$ at $0{ }^{\circ} \mathrm{C}$. The organic materials were extracted with $\mathrm{CH}_{2} \mathrm{Cl}_{2}$ and concentrated in vacuo. The conversions were determined from the ${ }^{1} \mathrm{H}$ NMR spectra of the crude reaction mixtures. The ee values were determined by chiral HPLC after preparative TLC (Chiralpak ${ }^{\circledR}$ AD-H column, hexane/2-propanol, 95:5, flow: $1.0 \mathrm{~mL} / \mathrm{min}, 220 \mathrm{~nm}$ ). Retention time $(\mathrm{min})=14.2[(R)-3], 16.4[(S)-3]$.

\section{(R)-4-(3-Chlorophenyl)-4-hydroxybutan-2-one (3)}

${ }^{1} \mathrm{H}$ NMR $\left(400 \mathrm{MHz}, \mathrm{CDCl}_{3}\right.$ ): $\delta=2.18$ (s, $3 \mathrm{H}$ ), 2.80-2.82 (m, $2 \mathrm{H}$ ), 5.10$5.12(\mathrm{~m}, 1 \mathrm{H}, \mathrm{CH}), 7.19-7.29(\mathrm{~m}, 4 \mathrm{H})$.

The analytical data are in accordance with those reported in the literature. ${ }^{5 c}$

\section{Funding Information}

EU-Research Project ONE-FLOW (“Catalyst Cascade Reactions in 'OneFlow' within a Compartmentalized, Green-Solvent 'Digital Synthesis Machinery' - End-to-End Green Process Design for Pharmaceuticals"), Work programme: EU proposal 737266.

\section{References}

(1) Present address: School of Chemical Engineering, The University of Adelaide, Adelaide, South Australia 5005, Australia.

(2) Reviews: (a) Rudroff, F.; Mihovilovic, M. D.; Gröger, H.; Snajdrova, R.; Iding, H.; Bornscheuer, U. T. Nat. Catal. 2018, 1, 12. (b) Schrittwieser, J. H.; Velikogne, S.; Hall, M.; Kroutil, W. Chem. Rev. 2018, 118, 270. (c) Gröger, H.; Hummel, W. Curr. Opin. Chem. Biol. 2014, 19, 171. (d) Denard, C. A.; Hartwig, J. F.; Zhao, H. ACS Catal. 2013, 3, 2856.

(3) (a) Wirth, T. Microreactors in Organic Chemistry and Catalysis; Wiley-VCH: Weinheim, 2013, 2nd Ed.. (b) Hessel, V.; Kralisch, D.; Kockmann, N.; Noël, T.; Wang, Q. ChemSusChem 2013, 6, 746. (c) Ley, S. V. Chem. Rec. 2012, 12, 378. (d) Plutschack, M. B.; Pieber, B.; Gilmore, K.; Seeberger, P. H. Chem. Rev. 2017, 107, 11796.

(4) (a) Woodcock, J. Modernizing Pharmaceutical Manufacturing Continuous Manufacturing as a Key Enabler; Lecture presented at the MIT-CMAC International Symposium on Continuous Manufacturing of Pharmaceuticals: Cambridge, MA, USA, 20.05.2014. (b) Hernan, D. Continuous Manufacturing: Challenges and Opportunities. EMA Perspective; Lecture presented at the 3rd FDA/PQRI Conference on Advancing Product Quality: Rockville, MD, USA, 22-24.03.2017.

(5) (a) Rulli, G.; Duangdee, N.; Hummel, W.; Berkessel, A.; Gröger, H. Eur. J. Org. Chem. 2017, 812. (b) Heidlindemann, M.; Rulli, G.; Berkessel, A.; Hummel, W.; Gröger, H. ACS Catal. 2014, 4, 1099. (c) Rulli, G.; Duangdee, N.; Baer, K.; Hummel, W.; Berkessel, A.; Gröger, H. Angew. Chem. Int. Ed. 2011, 50, 7944; Angew. Chem. 2011, 123, 8092. (d) Baer, K.; Kraußer, M.; Burda, E.; Hummel, W.; Berkessel, A.; Gröger, H. Angew. Chem. Int. Ed. 2009, 48, 9355, Angew. Chem. 2009, 121, 9519.

(6) (a) Raj, M.; Singh, V. K. Chem. Commun. 2009, 6687. (b) Raj, M.; Maya, V.; Ginotra, S. K.; Singh, V. K. Org. Lett. 2006, 8, 4097. (c) Maya, V.; Raj, M.; Singh, V. K. Org. Lett. 2007, 9, 2593. (d) Raj, M.; Maya, V.; Singh, V. K. J. Org. Chem. 2009, 74, 4289.

(7) (a) Duangdee, N.; Harnying, W.; Rulli, G.; Neudörfl, J.-M.; Gröger, H.; Berkessel, A. J. Am. Chem. Soc. 2012, 134, 11196. (b) For a continuous asymmetric aldol reaction in organic medium with a heterogenized organocatalyst, see: Rulli, G.; Fredriksen, K. A.; Duangdee, N.; Bonge-Hansen, T.; Berkessel, A.; Gröger, H. Synthesis 2013, 45, 2512.

(8) For a practical one-pot procedure toward a multigram-scale synthesis of organocatalyst 2 (Singh's catalyst), see: Berkessel, A.; Harnying, W.; Duangdee, N.; Neudörfl, J.-M.; Gröger, H. Org. Proc. Res. Dev. 2012, 16, 123.

(9) EU-Research Project ONE-FLOW ("Catalyst Cascade Reactions in 'One-Flow' within a Compartmentalized, Green-Solvent 'Digital Synthesis Machinery' - End-to-End Green Process Design for Pharmaceuticals"), Work programme: EU proposal 737266; see: one-flow.org (accessed Nov 28, 2018). 